\title{
A Global Marker Database for Phytophthora infestans
}

\author{
Gregory A. Forbes, International Potato Center (CIP); Stephen B. Goodwin, USDA-ARS, Department of Botany \\ and Plant Pathology, 1155 Lilly Hall, Purdue University, West Lafayette, IN 47907; André Drenth, CRC for Tropi- \\ cal Plant Pathology, The University of Queensland, Brisbane 4072, Australia; Pedro Oyarzun and Maria Eugenia \\ Ordoñez, International Potato Center (CIP), P.O. Box 17-21-1977, Quito, Ecuador; and William E. Fry, Depart- \\ ment of Plant Pathology, 334 Plant Science, Cornell University, Ithaca, NY 14853
}

\begin{abstract}
Forbes, G. A., Goodwin, S. B., Drenth, A., Oyarzun, P., Ordoñez, M. E., and Fry, W. E. 1998. A global marker database for Phytophthora infestans. Plant Dis. 82:811-818.

A marker database was compiled for isolates of the potato and tomato late blight pathogen, Phytophthora infestans, originating from 41 locations which include 31 countries plus 10 regions within Mexico. Presently, the database contains information on 1,776 isolates for one or more of the following markers: restriction fragment length polymorphism (RFLP) "fingerprint" consisting of 23 bands; mating type; dilocus allozyme genotype; mitochondrial DNA haplotype; sensitivity to the fungicide metalaxyl; and virulence. In the database, 305 entries have unique RFLP fingerprints and 258 entries have unique multilocus genotypes based on RFLP fingerprint, dilocus allozyme genotype, and mating type. A nomenclature is described for naming multilocus genotypes based on the International Organization for Standardization (ISO) two-letter country code and a unique number. Forty-two previously published multilocus genotypes are represented in the database with references to publications. As a result of compilation of the database, seven new genotypes were identified and named. Cluster analysis of genotypes from clonally propagated populations worldwide generally confirmed a previously published classification of "old" and "new" genotypes. Genotypes from geographically distant countries were frequently clustered, and several old and new genotypes were found in two or more distant countries. The cluster analysis also demonstrated that A2 genotypes from Argentina differed from all others. The database is available via the Internet, and thus can serve as a resource for Phytophthora workers worldwide.
\end{abstract}

Additional keywords: DNA fingerprints, population genetics, RG57
$P$. infestans also stimulated new hypotheses about historical migrations and the genetic structure of the global pathogen population (11). This information may be useful for interpreting changes in overall disease severity. For example, recent changes in the population structure of $P$. infestans have been linked with increased difficulty in the management of late blight in North America and Europe (8).

To date, most studies on $P$. infestans populations concerned North America and Europe (11) and produced detailed information on the pathogen populations in these areas. In contrast, little is known of the pathogen population structure in South America, Africa, and parts of Asia. As a result, many questions regarding the global population structure of this important plant pathogen remain unanswered (11).

For example, analysis of isolates from several countries for mating type, allozyme genotype, and DNA fingerprint led to the hypothesis that a single clonal lineage, US-
The development of molecular markers stimulated new insights into the genetic structure of plant pathogen populations $(13,17,19,23,24,32)$. Several markers, including the moderately repetitive nuclear restriction fragment length polymorphism (RFLP) probe RG57, have been particularly useful in population analysis of the potato and tomato late blight pathogen Phytophthora infestans (Mont.) deBary $(9,15,17,19,26-28)$. Knowledge of pathogen population structure has been used to develop or modify disease management strategies $(21,25)$ and in deployment of host resistance (22). Population studies on

Corresponding author: Gregory Forbes

E-mail: forbes@cip.org.ec

This work was supported in part by the Program in Science and Technology Cooperation, Office of the Science Advisor, United States Agency for International Development, Project 12.141, the International Potato Center, Cornell University, DuPont Co., USDA-ARS and NRI.

Accepted for publication 9 April 1998.

Publication no. D-1998-0520-03S

(C) 1998 The American Phytopathological Society

Table 1. Description of variables in the Phytophthora infestans global database

\begin{tabular}{|c|c|}
\hline Variable & Variable description \\
\hline \multicolumn{2}{|c|}{ Isolate identification } \\
\hline CORNELL & Cornell isolate code \\
\hline ISOLATE & Original isolate designation of contributing institution \\
\hline COUNTRY & Country where isolated \\
\hline ISO & International Organization for Standardization two-letter country code \\
\hline LOCATION & Region of country where isolated \\
\hline HOST & Potato, tomato, etc. \\
\hline CULTIVAR & Cultivar of host \\
\hline DATE & Date or year isolated \\
\hline COMMENT & Information not covered in the above variables \\
\hline \multicolumn{2}{|r|}{ 年 } \\
\hline MATING_T & Mating type ('A1', 'A2', or 'SF') \\
\hline GPI & Glucose-6-phosphate isomerase (Gpi) genotype \\
\hline PEP & Peptidase (Pep) genotype \\
\hline FING_PRT & DNA fingerprint ${ }^{\mathrm{a}}$ \\
\hline FP9A & DNA fingerprint band between bands 9 and $10^{\mathrm{b}}$ \\
\hline FP14A & DNA fingerprint band between bands 14 and $15^{b}$ \\
\hline FP24A & DNA fingerprint band between bands 24 and $25^{b}$ \\
\hline FP25A & DNA fingerprint band after band $25^{b}$ \\
\hline MT_DNA & Mitochondrial DNA pattern ${ }^{c}$ \\
\hline METALAX & Sensitivity to metalaxyl ('R', 'M', 'S') ${ }^{\mathrm{d}}$ \\
\hline VIRULENCE & Specific virulence on 11 known Solanum demissium R-genes \\
\hline \multicolumn{2}{|r|}{ P } \\
\hline GENOTYPE & Multilocus genotype name \\
\hline PUB_GEN & Published genotype name which is inconsistent with nomenclature ${ }^{\mathrm{e}}$ \\
\hline SOURCE & Original supplier of isolate, infected tissue or data \\
\hline REFERENCE & Where published initially \\
\hline \multicolumn{2}{|c|}{ a As determined with the moderately repetitive DNA probe RG57 (15). } \\
\hline \multicolumn{2}{|c|}{$\begin{array}{l}\text { b These are additional DNA fingerprint bands discovered after bands } 1 \text { to } 25 \text { were numbered. } \\
\text { c As described by Goodwin (10) or Carter et al (3). } \\
\text { d R = resistant, } M=\text { moderately resistant and } S=\text { sensitive, as described by Therrien et al. (29). } \\
\text { e Based on nomenclature described in Materials and Methods. }\end{array}$} \\
\hline
\end{tabular}


1, dominated most populations of $P$. infestans outside Mexico until recently (13). The universality of US-1 was clearly demonstrated with marker analyses (13), but its origin has been disputed (1). One interpretation of the data is that US-1 was intro- duced into the United States in the 1840s and subsequently to Europe, where it caused the devastating epidemics which were primary factors leading to the Irish Potato Famine (13). An alternative interpretation suggests that US-1 was intro-

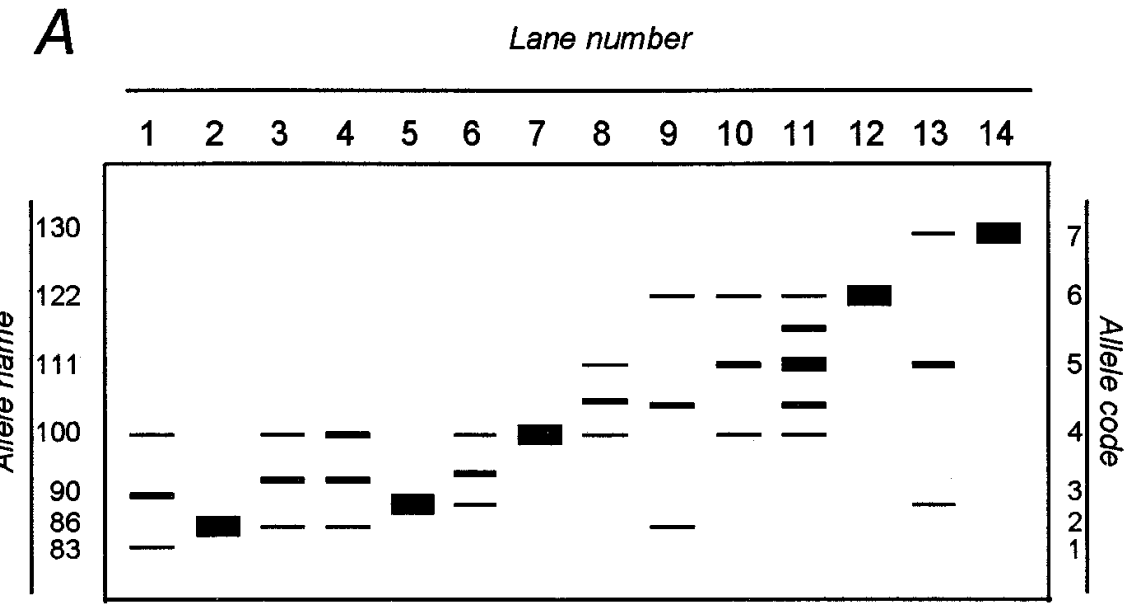

$\begin{array}{llllllllllllll}14 & 22 & 24 & 244 & 33 & 34 & 44 & 45 & 26 & 46 & 456 & 66 & 37 & 77\end{array}$

Genotype code

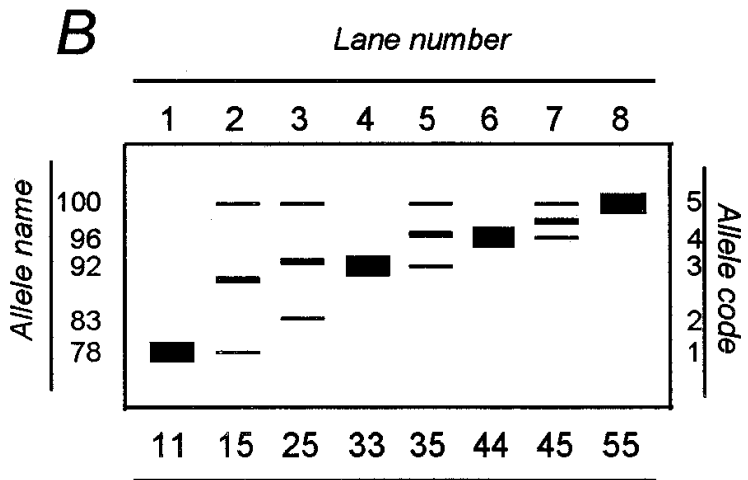

Genotype code

Fig. 1. Deciphering the allozyme genotypes of Phytophthora infestans: the Rosetta Stone. The most commonly detected genotypes worldwide are shown for (A) the Glucose-6-phosphate isomerase (Gpi) locus and (B) the Peptidase (Pep) locus. Both enzymes are dimeric, giving three bands for each heterozygous genotype: two homodimer bands and one heterodimer band. Homozygous genotypes have a single band. Genotypes are drawn approximately to scale assuming a migration distance of 5 $\mathrm{cm}$ for the 100/100 homodimer band at each locus. Allele names on the left indicate the approximate migration distance of each homodimer band. The coding for each allele is on the right. Allele codes are combined to form the genotype codes indicated at the bottom of each lane. The 14 lanes at the Gpi locus correspond to the following genotypes: lane 1,83/100; lane 2, 86/86; lane 3,86/100; lane 4, 86/100/100; lane 5, 90/90; lane 6, 90/100; lane 7, 100/100; lane 8, 100/111; lane 9, 86/122; lane 10, 100/122; lane 11,100/111/122; lane 12,122/122; lane 13,90/130; lane 14, 130/130. The eight lanes at the Pep locus correspond to the following genotypes: lane 1, 78/78; lane 2, 78/100; lane 3, 83/100; lane 4, 92/92; lane 5,92/100; lane 6, 96/96; lane 7, 96/100; lane 8, 100/100. Notice the two genotypes at the Gpi locus with three alleles: Gpi 86/100/100 (lane 4) and Gpi 100/111/122 (lane 11). The Gpi $86 / 100 / 100$ genotype gives an "unbalanced" heterozygote pattern with an approximately 1:4:4 ratio of intensities for bands representing the $86 / 86$ homodimer, $86 / 100$ heterodimer, and $100 / 100$ homodimer bands, respectively. Compare this to the "balanced" $86 / 100$ heterozygote pattern in lane 3 . The 100/111/122 genotype has five bands in an approximately 1:2:3:2:1 ratio of intensities (16). This is due to co-migration of the $111 / 111$ homodimer and 100/122 heterodimer bands. A possible additional allele has been found at the Pep locus (13). This allele was found in isolates from Costa Rica and has a migration distance of approximately $94 \%$ compared to the 100 allele between the Pep 92 and 96 alleles. However, this allele has not been confirmed by analyses with proper controls so was not included in the figure. It was coded Pep allele 6 in the database. This figure was meant to show typical idealized separation distances among the bands on a gel; actual distances between bands may vary due to the composition of the gel and $\mathrm{pH}$ of the buffers used.

duced into Europe and the United States from South America, where it had existed during pre-colonial times (1).

Answering this and other questions regarding the global population structure of $P$. infestans will depend, at least in part, on the availability of marker information from different parts of the world. One important step toward making this information available would be agreement on a nomenclature for genotype designations, standardization of genetic data, both in terms of markers used and the way data are stored, and compilation of marker data into one database which is readily available to all researchers.

The purpose of this paper is to propose standardization of $P$. infestans nomenclature and marker data, and compile a large amount of existing marker data into a single database, which will be available over the Internet. We also demonstrate how the database can be used to examine the relationship among genotypes from clonally propagated populations (clonal lineages). This analysis supports some earlier hypotheses and provides new information on the relatedness of genotypes in South America. This database should form a solid basis for future studies on the genetic structure of populations of $P$. infestans.

\section{MATERIALS AND METHODS}

Database. The database contains marker data from several published (4-6,9,1214,17-20,28) and unpublished studies (S. B. Goodwin and G. A. Forbes, unpublished). Isolate characteristics were entered into the database using 24 categories (Table 1). Eight identification variables contain typical passport data related to isolate history and maintenance. Unusual observations can be recorded in a variable for comments. There are 11 categories of marker data: mating type; dilocus allozyme genotype at the two loci glucose-6-phosphate isomerase (Gpi) and peptidase $(P e p)$; genomic DNA fingerprint as determined with probe RG57, including four separate variables for rare DNA fingerprint bands; mitochondrial DNA haplotype; sensitivity to the fungicide metalaxyl; and specific virulence. Data for allozyme genotypes and DNA fingerprints were coded as indicated in Figures 1 and 2, respectively. The final four categories contain summary information. One category indicates the multilocus genotype designation of each isolate, determined by analysis of the 23 RFLP fingerprint loci, dilocus allozyme genotype, and mating type. One variable retains previously published genotype designations which do not adhere to the nomenclature outlined in this paper. One category indicates the original source of the isolates or data, and the final category indicates the reference in which the data were published initially.

The database is easily expandable to accommodate additional markers that may 
prove useful in the future. The isolates were collected at different times and do not necessarily reflect the current populations of the countries in which they were collected. Some isolates listed in the database are currently available in a culture collection curated by W. E. Fry (Cornell University); however, many isolates are no longer available.

Comparison of genotypes from asexual populations. For countries where sexual reproduction has not been demonstrated, or demonstrated only very recently (all except Mexico, Poland, and the Netherlands), the units of analysis were the multilocus genotypes described above, which were constructed for each isolate and based on 23 RFLP fingerprint bands, mating type, and genotype at the Gpi and Pep allozyme loci. RFLP band 4, which has been scored inconsistently, and band 25 , which occurred in all fingerprints, were excluded from analyses.

Each RFLP band was treated as one dichotomous variable, with values of 0 or 1 for absence and presence, respectively. Data for allozyme genotypes were converted to binary format by creating a dichotomous variable with values of 0 or 1 (absence or presence) for each known allele (seven for Gpi and six for Pep). Similarity of multilocus genotypes in asexual populations was estimated with the Jaccard coefficient (31), which was then subtracted from unity to represent genetic distance. Trees were constructed from the distance matrix using the unweighted pair-group method of averages (UPGMA) algorithm. All analyses were done using SAS (release 6.12, SAS Institute, Inc., Cary, NC).

\section{RESULTS}

At present, the database contains information on isolates from 41 locations, including 31 countries plus 10 regions within Mexico (Table 2). There are 1,776 entries, of which 1,227 have RFLP fingerprints, based on a minimum common set of 23 bands. Overall, 369 RFLP fingerprints are unique within their respective sites (Table 2 ), although some of these occur in more than one site. There are 305 unique RFLP fingerprints in the entire database. Among 976 isolates with complete data for RFLP fingerprint, dilocus allozyme genotype, and mating type, there are 288 multilocus genotypes which are unique within their respective site (Table 2), and 258 which are unique in the database. The number of unique multilocus genotypes is smaller than the number of unique RFLP fingerprints because some entries which have RFLP data do not have allozyme data. Most of the unique multilocus genotypes come from Mexico, the Netherlands, and Poland, where sexual recombination is known to occur $(4,28,30)$. There is also a large number of unique genotypes from the United States and Canada, for which there is evidence of repeated introductions of

\section{Genotype}

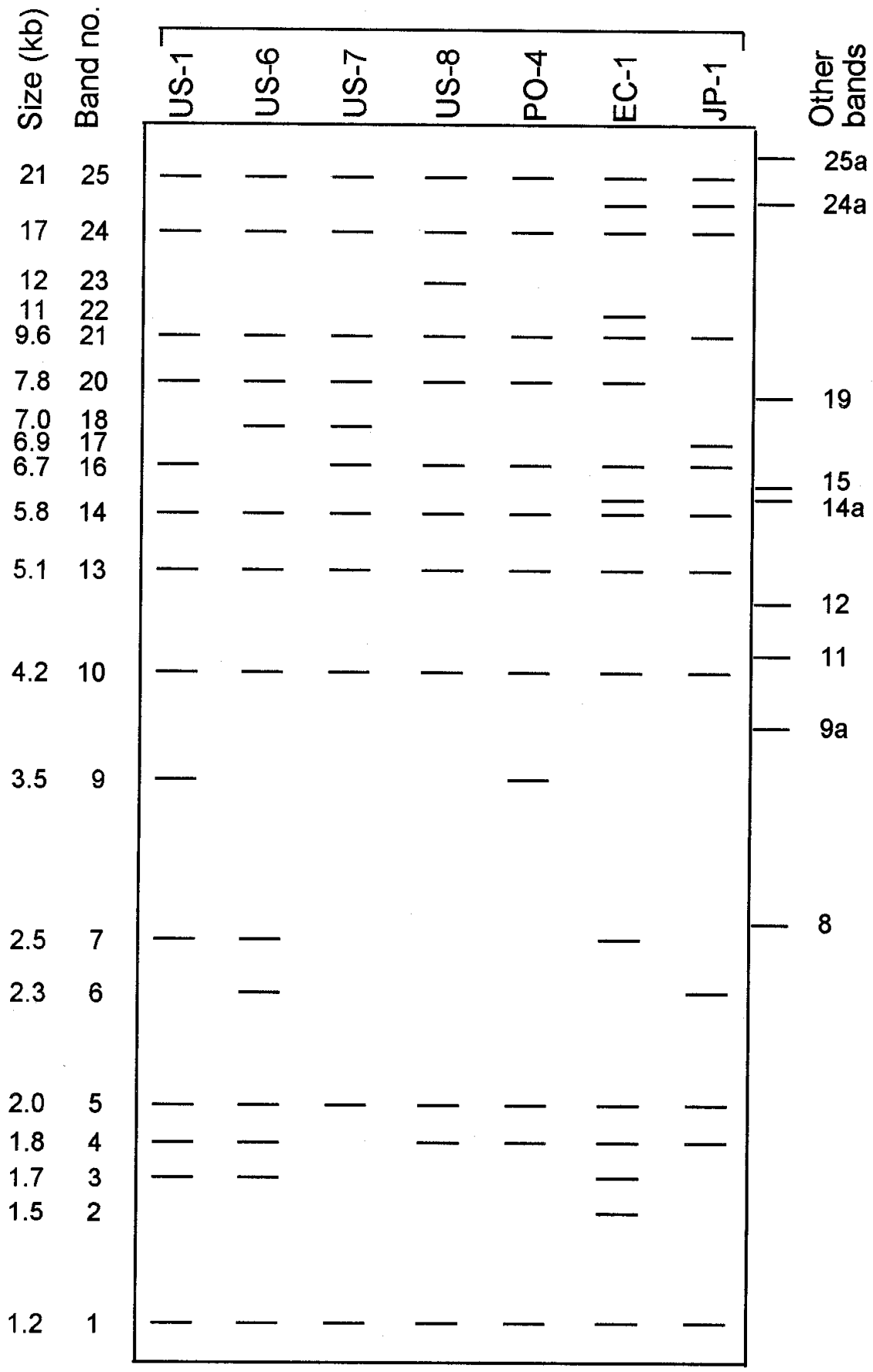

Fig. 2. Coding of DNA fingerprint genotypes of Phytophthora infestans for the global database. Fingerprint patterns are as generated using the moderately repetitive probe RG57 as described elsewhere (15). Each band represents a different genetic locus that segregates for the presence or absence of a band (15). Approximate band positions are indicated for all seven genotypes that occurred 10 or more times in the global database. Each genotype was the most commonly detected clone in the following locations: US-1, worldwide (11,13); US-6, US-7, and US-8, the United States and Canada (12,17); PO-4, eastern Europe (28); EC-1, northern South America (5,25); and JP-1, east Asia (20). The major bands in each genotype (in bold) and their approximate sizes in kilobases are indicated on the left. The approximate positions of bands not present in these genotypes or that are rare are indicated by the arrows on the right. For the database, fingerprint genotypes were coded where $0=$ absence and $1=$ presence of a band at each fingerprint locus. Some investigators scored presence with 1 for a probable heterozygote and 2 for a probable homozygote; both types of scoring are present in the database and were scored as 1 for the analyses. By tilting the figure 90 degrees clockwise, the genotypes can be read from left to right like a bar code. The location of band 4 was indicated to be consistent with previous publications. However, this band is not always repeatable and seems to depend on the particular batch of probe used. Therefore, variation at fingerprint locus 4 is difficult to interpret and should be excluded from all analyses. This schematic is drawn to scale from a real gel but is intended for illustration only; actual migration distances will vary depending on the gel conditions used. 
new genotypes from Mexico $(12,17,19)$, and recent evidence for probable sexual reproduction (17). The US-1 genotype was found in 20 countries worldwide (Table 2).

Nomenclature. We propose the use of multilocus genotype designations, consisting of the internationally accepted, twoletter code from the International Organization for Standardization (ISO) for the country where the genotype was isolated and a unique number. This system is in agreement with an earlier genotype designation for US-1 by Goodwin et al. (13) using the same markers. Once a genotype has been identified, its designation is used wherever it is subsequently found. For example, US-1 was originally identified in the United States, but it has subsequently been found in many countries where it retains the US-1 designation (13). A few previously published genotype names are not consistent with this nomenclature $(12,17)$. These genotypes were given new names consistent with the nomenclature; the old names have been maintained in the database as a separate variable.

An extension of the nomenclature described above was adopted by Goodwin et al. (12) to identify genotypes which have arisen from within a single clonal lineage. These genotypes are identical to other members of the same clonal lineage except for changes at one, or at most two, allozyme or DNA fingerprint loci. They are identified by placing a decimal point and a number after the genotype name. For example, US-1.1 and US-1.2 are variants within the US-1 lineage, while US-6.1 is a genotype which has developed within the US-6 lineage.

Currently, the database contains 42 multilocus genotypes which were published previously (Table 3 ).

An additional seven previously unnamed genotypes were identified after compilation of this database (Table 4). These were given designations based on the country where the genotypes were found and a unique number as described above.

Comparison of multilocus genotypes. Clustering of multilocus genotypes from clonally propagated populations generally corroborated the classification of "old" and "new" genotypes proposed by Spielman et al (27). One large cluster was formed by

Table 2. Summary statistics and frequencies of restriction fragment length polymorphism (RFLP) and multilocus genotypes found in sites represented in the global marker database for Phytophthora infestans

\begin{tabular}{|c|c|c|c|c|c|c|c|}
\hline \multirow[b]{2}{*}{ Country or regiona } & \multirow[b]{2}{*}{ ISO code $\mathrm{e}^{\mathrm{b}}$} & \multirow[b]{2}{*}{ Entries $^{c}$} & \multicolumn{2}{|c|}{ Genotypes } & \multicolumn{3}{|c|}{ Mating type } \\
\hline & & & RFLPd $^{d}$ & $\mathbf{M L}^{\mathrm{e}}$ & A1 & $\mathbf{A 2}$ & $\mathbf{S F}^{\mathrm{f}}$ \\
\hline Argentina & $\mathrm{AR}$ & 15 & 2 & 5 & 0 & 15 & 0 \\
\hline Australia & $\mathrm{AU}$ & 5 & 2 & 2 & 5 & 0 & 0 \\
\hline Byelorussia & BY & 7 & 1 & 1 & 7 & 0 & 0 \\
\hline Bolivia & $\mathrm{BO}$ & 1 & 1 & 1 & 0 & 1 & 0 \\
\hline Brazil** & $\mathrm{BR}$ & 7 & 2 & 4 & 4 & 3 & 0 \\
\hline Canada** & $\mathrm{CA}$ & 75 & 13 & 12 & 66 & 8 & 0 \\
\hline China** & $\mathrm{CN}$ & 6 & 1 & 1 & 6 & 0 & 0 \\
\hline Colombia** & $\mathrm{CO}$ & 12 & 2 & 2 & 12 & 0 & 0 \\
\hline Costa Rica & $\mathrm{CR}$ & 9 & 1 & 1 & 8 & 0 & 0 \\
\hline Ecuador** & $\mathrm{EC}$ & 74 & 2 & 2 & 74 & 0 & 0 \\
\hline Estonia & $\mathrm{EE}$ & 2 & 1 & 2 & 1 & 0 & 0 \\
\hline France & FR & 14 & 8 & 1 & 14 & 0 & 0 \\
\hline Germany** & $\mathrm{DE}$ & 16 & 2 & 0 & 16 & 0 & 0 \\
\hline Guatemala & GT & 1 & 0 & 0 & 0 & 1 & 0 \\
\hline Ireland $* *$ & IE & 2 & 1 & 1 & 2 & 0 & 0 \\
\hline Israel & IL & 9 & 1 & 1 & 0 & 9 & 0 \\
\hline Italy** & IT & 1 & 1 & 0 & 1 & 0 & 0 \\
\hline Japan** & JP & 30 & 2 & 2 & 15 & 15 & 0 \\
\hline Korea** & $\mathrm{KR}$ & 56 & 2 & 2 & 1 & 55 & 0 \\
\hline Mexico & MX & & & & & & \\
\hline Central Mexico & & 6 & 5 & 5 & 2 & 4 & 0 \\
\hline Chapingo & & 9 & 6 & 6 & 5 & 4 & 0 \\
\hline Chiapas & & 11 & 3 & 6 & 11 & 0 & 0 \\
\hline Los Mochis & & 88 & 3 & 4 & 63 & 25 & 0 \\
\hline Michoacan & & 10 & 3 & 3 & 7 & 3 & 0 \\
\hline Nuevo Leon & & 4 & 1 & 1 & 4 & 0 & 0 \\
\hline Puebla & & 26 & 11 & 1 & 15 & 11 & 0 \\
\hline Saltillo & & 41 & 13 & 1 & 13 & 27 & 1 \\
\hline Toluca & & 111 & 55 & 63 & 63 & 43 & 0 \\
\hline Vera Cruz & & 12 & 2 & 3 & 11 & 1 & 0 \\
\hline Netherlands $* *$ & NL & 211 & 131 & 11 & 107 & 99 & 2 \\
\hline Peru** & $\mathrm{PE}$ & 45 & 4 & 4 & 45 & 0 & 0 \\
\hline Philippines** & $\mathrm{PH}$ & 28 & 1 & 2 & 28 & 0 & 0 \\
\hline Poland** & PL & 251 & 62 & 81 & 189 & 42 & 5 \\
\hline Romania & RO & 1 & 0 & 0 & 0 & 1 & 0 \\
\hline Russia** & RU & 7 & 2 & 3 & 3 & 4 & 1 \\
\hline Rwanda** & RW & 21 & 3 & 4 & 21 & 0 & 0 \\
\hline Spain & ES & 2 & 1 & 1 & 2 & 0 & 0 \\
\hline Switzerland** & $\mathrm{CH}$ & 3 & 1 & 1 & 3 & 0 & 0 \\
\hline Taiwan** & TW & 3 & 1 & 1 & 3 & 0 & 0 \\
\hline United Kingdom** & GB & 16 & 4 & 2 & 15 & 1 & 0 \\
\hline United States** & US & 528 & 12 & 16 & 276 & 236 & 0 \\
\hline Total & & 1,776 & 369 & 288 & 1,118 & 608 & 9 \\
\hline
\end{tabular}

${ }^{\text {a }}$ Locations indicated with ** have the US-1 genotype.

${ }^{\mathrm{b}}$ International Organization for Standardization, Alpha 2 code.

${ }^{c}$ Number of isolates.

${ }^{d}$ Number of RFLP fingerprints which are unique within each site. Genotypes based on 23 RFLP bands.

e Number of multilocus genotypes within each site. Genotypes based on 23 RFLP bands, dilocus allozyme genotype, and mating type.

${ }^{\mathrm{f}}$ Self fertile. 
Table 3. Previously published multilocus genotypes ${ }^{\mathrm{a}}$ which are currently represented in the database

\begin{tabular}{|c|c|c|c|c|c|}
\hline Genotype & Mating type & $G p i^{\mathrm{b}}$ & $P e p^{\mathrm{c}}$ & RFLP fingerprint ${ }^{d}$ & Source \\
\hline AU-1 & A1 & 24 & 55 & 1001100001001101010110011 & (13) \\
\hline AU-2 & A1 & 24 & 55 & 1011101000001100000110011 & (13) \\
\hline BR-1 & A2 & 44 & 55 & 1011101000001100001111011 & (13) \\
\hline CA-1 & A1 & 24 & 35 & 1111101011001101001110011 & (12) \\
\hline CA-2 & A1 & 44 & 55 & 1011001000001100001110011 & (12) \\
\hline CA- 2.1 & A1 & 44 & 55 & 1011001000001100001111011 & (12) \\
\hline CA-3 & A2 & 24 & 55 & 1111101001001001100110011 & (12) \\
\hline CA-4 & A2 & 45 & 55 & 1001000001001101000110011 & (17) \\
\hline CA-5 & A2 & 44 & 55 & 1000110000001101000110011 & (17) \\
\hline CA-6 & A2 & 44 & 55 & 1010001001001100010110011 & (17) \\
\hline CA-7 & A2 & 44 & 55 & 1001000000001100010110011 & (17) \\
\hline CR-1 & A1 & 44 & 56 & 1001000001001101000110011 & (14) \\
\hline EC-1 & A1 & 34 & 45 & 1111101001001101000111011 & (5) \\
\hline EE-1 & $\mathrm{A} 1$ & 34 & 55 & 1001100001001100100110011 & (17) \\
\hline EE-2 & SF & 34 & 55 & 1010101011001101000110011 & (14) \\
\hline IL-1 & A2 & 44 & 55 & 1001100001001101000110011 & (13) \\
\hline JP-1 & A2 & 44 & 44 & 1001110000001101100010011 & (18) \\
\hline RU-1 & A1 & 44 & 55 & 1011101011001101000110011 & (14) \\
\hline RW-1 & A1 & 34 & 25 & 1111111011001101001111011 & (13) \\
\hline RW-2 & A1 & 34 & 55 & 1111101001001101001111011 & (13) \\
\hline US-1 & A1 & 24 & 35 & 1011101011001101000110011 & (13) \\
\hline US-1.1 & A1 & 24 & 55 & 1011101011001101000110011 & (28) \\
\hline US-1.2 & A1 & 24 & 35 & 1011101010001101000110011 & (13) \\
\hline US-1.3 & A1 & 24 & 35 & 1011101001001101000110011 & (13) \\
\hline US-1.4 & A1 & 24 & 55 & 1011101010001101000110011 & (12) \\
\hline US-1.5 & $\mathrm{A} 1$ & 24 & 35 & 1011101011001101010110011 & (17) \\
\hline US-1.6 & A1 & 24 & 35 & 1011101011001101000111011 & (14) \\
\hline US-1.7 & A1 & 44 & 35 & 1011101011001101000110011 & (14) \\
\hline US-2 & A1 & 24 & 35 & 1011101001001101011110011 & (12) \\
\hline US-3 & A1 & 24 & 35 & 1011100000001101000110011 & (12) \\
\hline US-4 & A1 & 44 & 33 & 1011101001001101100110011 & (12) \\
\hline US-5 & A1 & 44 & 35 & 1011101001001101011110011 & (12) \\
\hline US-6 & A1 & 44 & 35 & 1011111001001100010110011 & (17) \\
\hline US-6.1 & A1 & 44 & 33 & 1011111001001100010110011 & (12) \\
\hline US-6.2 & A1 & 44 & 35 & 1011101001001100010110011 & (12) \\
\hline US-6.3 & A1 & 44 & 35 & 1011111001011100010110011 & (12) \\
\hline US-6.4 & A1 & 44 & 55 & 1011011001001100010110011 & (12) \\
\hline US-6.5 & A1 & 44 & 35 & 1011111001001100010010011 & (12) \\
\hline US-7 & A2 & 45 & 55 & 1011101011001101000110011 & (17) \\
\hline US-8 & 44 & A2 & 456 & 1001100001001101000110111 & (17) \\
\hline US-9e & A1 & 44 & 25 & $\ldots$ & (17) \\
\hline US $-10^{\mathrm{e}}$ & A2 & 56 & 55 & $\ldots$ & (17) \\
\hline
\end{tabular}

${ }^{a}$ Genotypes based on 23 restriction fragment length polymorphism (RFLP) bands, dilocus allozyme genotype, and mating type. New names exist in the database for certain genotypes which do not concur with the proposed nomenclature (for example, Canadian genotype CDA-1 has been changed to CA-1). Originally published names have been retained in the database to facilitate cross referencing. Allozyme genotypes and DNA fingerprints are coded as indicated in Figs. 1 and 2, respectively.

${ }^{\mathrm{b}}$ Glucose-6-phosphate isomerase. Alleles at the Gpi locus are coded as $86=2,90=3,100=4,111$ $=5$, and $122=6$.

${ }^{c}$ Peptidase. Alleles at the Pep locus are coded as $83=2,92=3,96=4$, and $100=5$.

${ }^{\mathrm{d}}$ DNA fingerprint bands revealed by the moderately repetitive probe RG57 (15) Presence and absence of bands are indicated by 1 and 0, respectively. Bands 1 to 25 are listed from left to right. Bands 4 and 25 were not used in analyses.

e US-9 and 10 are based on novel Gpi and Pep patterns. RFLP fingerprints are not known.

Table 4. Multilocus genotypes ${ }^{\mathrm{a}}$ named as a result of compilation of the database

\begin{tabular}{lcccc}
\hline Genotype & Mating type & $\boldsymbol{G p i}^{\mathbf{b}}$ & $\boldsymbol{P e p}^{\mathbf{c}}$ & RFLP fingerprint $^{\mathbf{d}}$ \\
\hline AR-1 & A2 & 44 & 34 & 1001000000000000000111111 \\
AR-2 & A2 & 44 & 44 & 1001000000000000000111111 \\
AR-3 & A2 & 44 & 34 & 1001100010000000000101111 \\
AR-4 & A2 & 44 & 44 & 1001100010000000000101111 \\
AR-5 & A2 & 44 & 45 & 1001100010000000000101111 \\
FR-1 & A1 & 44 & 25 & 1010111111001101001110101 \\
ES-1 & A1 & 34 & 55 & 1100100001001101000110011 \\
\hline
\end{tabular}

${ }^{\text {a }}$ Genotypes based on 23 restriction fragment length polymorphism (RFLP) bands, dilocus allozyme genotype, and mating type.

${ }^{\mathrm{b}}$ Glucose-6-phosphate isomerase. Alleles at the Gpi locus are coded as $90=3$ and $100=4$.

${ }^{c}$ Peptidase. Alleles at the Pep locus are coded as $83=2,92=3,96=4$ and $100=5$.

${ }^{\mathrm{d}}$ DNA fingerprint bands revealed by the moderately repetitive probe RG57 (15). Presence and absence of bands are indicated by 1 and 0 , respectively. Bands 1 to 25 are listed from left to right. Bands 4 and 25 were not used in analyses. old genotypes which belong to the US-1 lineage (Fig. 3). Old genotypes from the United States and Canada which do not belong to the US-1 lineage clustered together and adjacent to the US-1 lineage cluster. One previously described genotype from Russia (RU-1) clustered among the US-1 lineage genotypes and may belong to that lineage. The classification system of Spielman et al. (27) originally was based on mating type and dilocus allozyme genotype. This analysis confirms that it is also generally valid after examination of a more complex multilocus genotype including RFLP fingerprints.

New genotypes generally clustered according to mating type. Genotype CA-3 from Canada was an exception, because it was not closely associated with any other A2 genotypes (Fig. 3).

The cluster analyses indicated some degree of geographical structuring (genotypes from Argentina, and some from Canada and the United States, were closely clustered), but there was also clustering of genotypes from distant countries. One genotype from Rwanda was most closely associated with EC-1 from the Andean region. BR-1 from Brazil and Bolivia (13) was most closely associated with genotypes CA-2.1 and CA-2 from Canada. In addition to showing other close associations among genotypes from geographically distant sites, the cluster analysis indicated that genotype PO-57, first named in Poland but also found in Russia, is identical to IL-1 from Israel.

Compilation of the database also demonstrated that several genotypes are distributed internationally (Table 5). In some cases, the same genotype has been found in neighboring countries. For example, EC-1 is found in Colombia and Ecuador, JP-1 in Japan and South Korea, US-6 in Canada and the United States. Some genotypes, however, are globally distributed. The global distribution of US-1 was demonstrated previously (13) and the genotype is shown here to occur in 20 countries (Table 2). Genotypes thought to have developed within the US-1 lineage (US-1.1, US-1.2, US-1.3) also occur on several continents (Table 5). It is not possible to tell from this analysis whether the global distribution of these genotypes is a result of migration or whether they have developed independently from the US-1 genotype within each site.

The cluster analysis of asexual populations sheds new light on the genetic structure of the population of $P$. infestans in South America. The A2 mating type had been reported for Brazil (2), Bolivia (13), and Argentina (7), but nothing was known of the relatedness of these populations. Here it is shown that the A2 isolates from both Brazil and Bolivia are the same genotype, BR-1. The A2 genotypes from Argentina are related among themselves but distinct from BR-1. The small number 
of samples represented in the database from each of these countries (Table 2) makes it impossible to comment on the presence of other genotypes in this region. US-1 also occurs in Brazil (13), but to date it has only been found on tomato (2). The EC-1 lineage which was recently described in Ecuador (5) is seen here to extend north to Colombia. The US-1 lineage also occurs in these countries and Peru (Table 2).

\section{DISCUSSION}

The database compiled here is an important tool for studying the global population structure of $P$. infestans. It will be of utility to researchers who wish to examine global population patterns or compare local genotypes with a large international collection. The cluster analysis is one example of how this database can be used for assessing the relatedness among genotypes from clonal populations.

Most of the genetic diversity represented in the database is associated with North America and Europe (Table 2). In part, this reflects the global population structure of the pathogen. The presence of both mating types, and associated sexual recombination, in Mexico and Europe certainly has contributed to the large number of genotypes which have been found in those areas. Nonetheless, the information in the database also reflects a geographic imbalance in research activity, because very little sampling and marker analyses have been done outside North America, Europe, and a few locations in Asia. More information on the $P$. infestans populations in Africa, South America, and Asia could assist researchers in the development of improved disease management strategies. Information gained from pathogen population studies in the past has led to recommendations for refinement or modification of disease management approaches $(21,25)$. Knowledge of pathogen population structure also can play a key role in selection and deployment of durable host resistance (22).

The resurgence of late blight in North America and increased severity in Europe (8) has heightened interest among researchers. Genetic characterization of $P$. infestans isolates undoubtedly will be conducted by an increasing number of laboratories. Agreement on nomenclature and data storage structure will greatly facilitate comparative studies. Failure to agree on nomenclature will probably lead to confusion, reduced complementarity, and even unnecessary replication of research activities.

The nomenclature explicitly proposed here is based on earlier genotype designations (13). It is simple, yet provides for an unambiguous identification of genotypes. Incorporation of existing and future marker data into one database will help ensure standardization of data format as well as

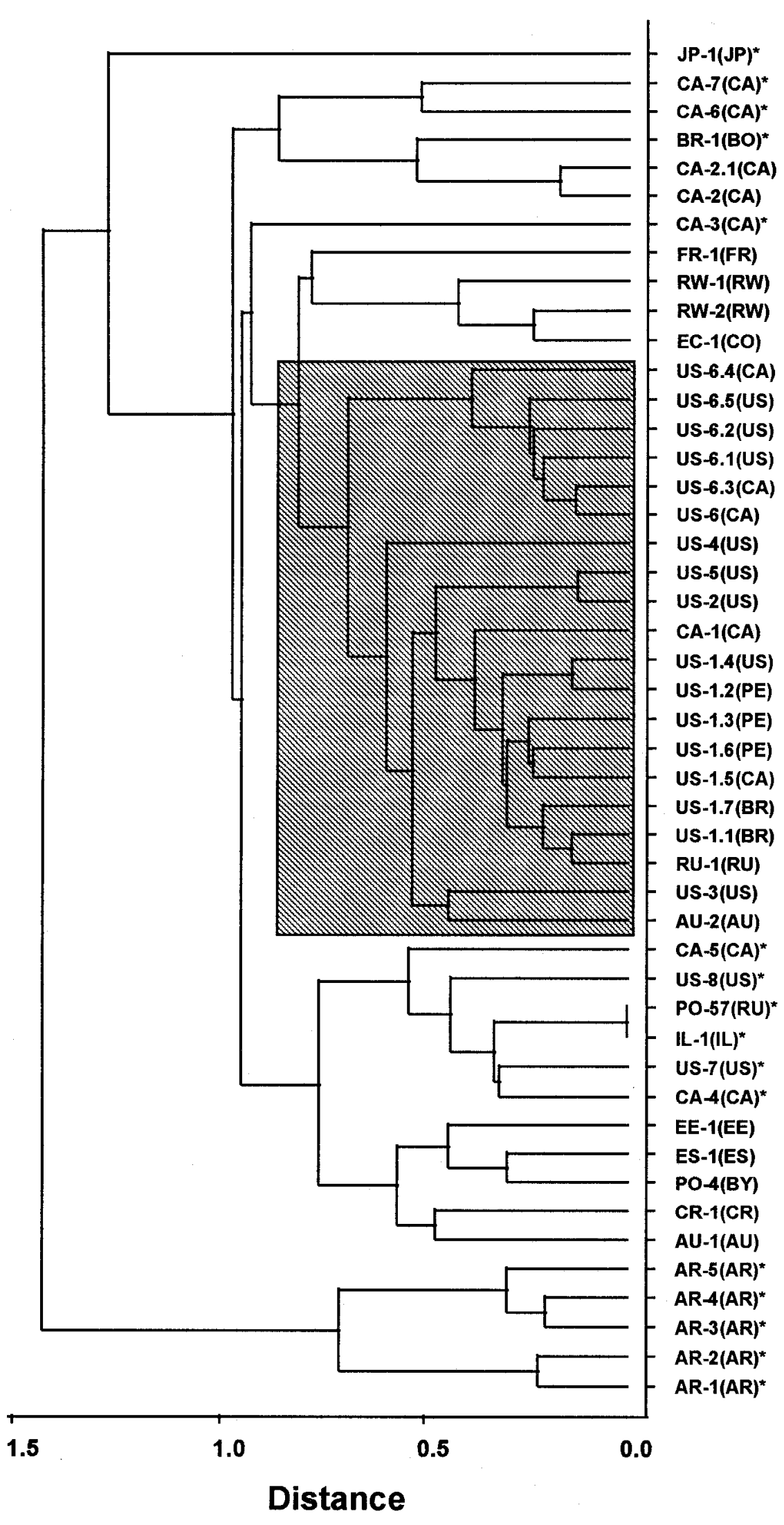

Fig. 3. Cluster analysis of asexual genotypes of Phytophthora infestans based on a distance coefficient (Jaccard) for multilocus genotypes consisting of restriction fragment length polymorphism fingerprint, mating type, and dilocus allozyme genotype. Genotype labels are the International Organization for Standardization (ISO) two-letter country code plus a unique number (see Table 2). ISO codes in parentheses indicate country where genotypes were found. Shaded area identifies "old" genotypes (27). Asterisks indicate A2 genotypes. Vertical lines indicate absolute ties where two or more isolates have the same genotype. 
nomenclature. One limitation to this system is that it is directly linked to the markers used to define genotypes. Addition of new marker information may differentiate among isolates which now have the same genotype designation. This problem should be addressed by those utilizing new marker technologies.

The utility of this database was demonstrated with one cluster analysis (Fig. 3). Even though this analysis was intended as an example, it generally confirmed the previously published classification of old and new genotypes and led to new observations regarding the global population structure of $P$. infestans. For example, one relevant statement can be made concerning management of the disease in South America. To date, only A2 genotypes have been found in association with potato production in Bolivia and only A1 genotypes have been found in association with potato production in Peru. Potato production is continuous across the border between Peru and Bolivia, and potato seed is traded between the two countries (J. Landeo, personal communication). Therefore, the potato production zones near the border between Peru and Bolivia represent an area were the $\mathrm{A} 1$ and $\mathrm{A} 2$ mating types could come in contact, perhaps for the first time, in the center of origin of potato. The increased genetic diversity resulting from sexual recombination and the epidemiological consequences of oospores may create new disease management problems for farmers in this important potato-growing region. Researchers should also be aware of new threats that increased pathogenic fitness of this pathogen may pose for wild tuber-bearing solanaceous species in the

Table 5. Multilocus genotypes from asexual populations represented by more than one country in the database

\begin{tabular}{lr}
\hline Genotype & Country \\
\hline Old genotypes & Russia \\
RU-1 & Rwanda \\
& Brazil \\
Canada \\
US-1.1 & Philippines \\
& United States \\
& Peru \\
US-1.2 & United Kingdom \\
& United States \\
& Peru \\
US-1.3 & United States \\
& Bolivia \\
New genotypes & Brazil \\
BR-1 & Japan \\
& Korea \\
JP-1 & Poland \\
& Byelorussia \\
PO-4 & Poland \\
& Israel \\
PO-57 & Russia \\
& Ecuador \\
EC-1 & Colombia \\
\hline
\end{tabular}

Andes, an important natural resource for the future.

Database availability. The database is available over the Internet via the Microbial Germplasm Database maintained at Oregon State University. To ensure that data standardization is maintained, we propose that anyone wishing to contribute new information first contact the corresponding author.

\section{ACKNOWLEDGMENTS}

We thank P. Nicholson, University of Leeds, for the SAS code used to produce the dendrogram of the cluster analysis.

\section{LITERATURE CITED}

1. Andrivon, D. 1996. The origin of Phytophthora infestans populations present in Europe in the 1840s: A critical review of historical and scientific evidence. Plant Pathol. 45:1027-1035.

2. Brommonschenkel, S. H. 1988. Pathogenicity, compatibility, cytogenetics and isoenzyme patterns of Brazilian isolates of Phytophthora infestans (Mont.) de Bary. M.S. Thesis, Universidade Federal de Viçosa, Viçosa, Brazil.

3. Carter, D. A., Archer, S. A., and Buck, K. W. 1990. Restriction fragment length polymorphisms of mitochondrial DNA of Phytophthora infestans. Mycol. Res. 94:11231128.

4. Drenth, A., Tas, I. C. Q., and Govers, F. 1994. DNA fingerprinting uncovers a new sexually reproducing population of Phytophthora infestans in the Netherlands. Eur. J. Plant Pathol. 100:97-107.

5. Forbes, G. A., Escobar, X. C., Ayala, C. C., Revelo, J., Ordoñez, M. E., Fry, B. A., Doucett, K., and Fry, W. E. 1997. Population genetic structure of Phytophthora infestans in Ecuador. Phytopathology 87:375-380.

6. Fry, W. E., Drenth, A., Spielman, L. J., Mantel, B. C., Davidse, L. C., and Goodwin, S. B. 1991. Population genetic structure of Phytophthora infestans in the Netherlands. Phytopathology 81:1330-1336.

7. Fry, W. E., and Goodwin, S. B. 1995. Recent migrations of Phytophthora infestans. Pages 89-95 in: Phytophthora infestans 150. L. J. Dowley, E. Bannon, L. R. Cooke, T. Keane, and E. O'Sullivan, eds. Boole Press, Dublin.

8. Fry, W. E., and Goodwin, S. B. 1997. Resurgence of the Irish potato famine fungus. BioScience 47:363-371.

9. Fry, W. E., Goodwin, S. B., Dyer, A. T., Matuszak, J. M., Drenth, A., Tooley, P. W., Sujkowski, L. S., Koh, Y. J., Cohen, B. A., Spielman, L. J., Deahl, K. L., Inglis, D. A., and Sandlan, K. P. 1993. Historical and recent migrations of Phytophthora infestans: Chronology, pathways, and implications. Plant Dis. 77:653-661.

10. Goodwin, S. B. 1991. DNA polymorphisms in Phytophthora infestans: the Cornell experience. Pages 256-271 in: Phytophthora. J. A. Lucas, R. C. Shattock, D. S. Shaw, and L. R. Cooke, eds. Cambridge University Press, Cambridge.

11. Goodwin, S. B. 1997. The population genetics of Phytophthora. Phytopathology 87:462473.

12. Goodwin, S. B., Cohen, B. A., Deahl, K. L., and Fry, W. E. 1994. Migration from northern Mexico as the probable cause of recent genetic changes in populations of Phytophthora infestans in the United States and Canada. Phytopathology 84:553-558.

13. Goodwin, S. B., Cohen, B. A., and Fry, W. E. 1994. Panglobal distribution of a single clonal lineage of the Irish potato famine fungus.
Proc. Natl. Acad. Sci. USA 91:11591-11595.

14. Goodwin, S. B., and Drenth, A. 1997. Origin of the A2 mating type of Phytophthora infestans outside of Mexico. Phytopathology 87:992-999.

15. Goodwin, S. B., Drenth, A., and Fry, W. E. 1992. Cloning and genetic analyses of two highly polymorphic, moderately repetitive nuclear DNAs from Phytophthora infestans. Curr. Genet. 22:107-115.

16. Goodwin, S. B., Spielman, L. J., Matuszak, J. M., Bergeron, S. N., and Fry, W. E. 1992. Clonal diversity and genetic differentiation of Phytophthora infestans populations in northern and central Mexico. Phytopathology 82:955-961.

17. Goodwin, S. B., Sujkowski, L. S., Dyer, A. T., Fry, B. A., and Fry, W. E. 1995. Direct detection of gene flow and probable sexual reproduction of Phytophthora infestans in northern North America. Phytopathology 85:473-479.

18. Goodwin, S. B., Sujkowski, L. S., and Fry, W. E. 1995. Rapid evolution of pathogenicity within clonal lineages of the potato late blight disease fungus. Phytopathology. 85:669-676.

19. Goodwin, S. B., Sujkowski, L. S., and Fry, W. E. 1996. Widespread distribution and probable origin of resistance to metalaxyl in clonal genotypes of Phytophthora infestans in the United States and western Canada. Phytopathology 86:793-800.

20. Koh, Y. J., Goodwin, S. B., Dyer, A. T., Cohen, B. A., Ogoshi, A., Sato, N., and Fry, W. E. 1994. Migrations and displacements of Phytophthora infestans populations in east Asian countries. Phytopathology 84:922-927.

21. Legard, D. E., Lee, T. Y., and Fry, W. E. 1995 Pathogenic specialization in Phytophthora infestans: Aggressiveness on tomato. Phytopathology 85:1356-1361.

22. Leung, H., Nelson, R. J., and Leach, J. E. 1993. Population structure of plant pathogenic fungi and bacteria. Pages 157-205 in: Advances in Plant Pathology. Academic Press, New York.

23. McDonald, B. A., and McDermott, J. M 1993. Population genetics of plant pathogenic fungi. BioScience 43:311-319.

24. Milgroom, M. G., and Lipari, S. E. 1995. Population differentiation in the chestnut blight fungus, Cryphonectria parasiticia, in eastern North America. Phytopathology 85:155-160.

25. Oyarzun, P. J., Pozo, A., Ordoñez, M. E., Doucett, K., and Forbes, G. A. 1997. Host specificity of Phytophthora infestans on tomato and potato in Ecuador. Phytopathology 88:265-271.

26. Spielman, L. J. 1991. Isoenzymes and population genetics of Phytophthora infestans. Pages 231-241 in: Phytophthora. R. C. Shattock, D. S. Shaw, L. R. Cook, and J. A. Lucas, eds. Cambridge University Press, Cambridge.

27. Spielman, L. J., Drenth, A., Davidse, L. C., Sujkowski, L. J., Gu, W., Tooley, P. W., and Fry, W. E. 1991. A second world-wide migration and population displacement of Phy tophthora infestans? Plant Pathol. 40:422430.

28. Sujkowski, L. S., Goodwin, S. B., Dyer, A. T., and Fry, W. E. 1994. Increased genotypic diversity via migration and possible occurrence of sexual reproduction of Phytophthora infestans in Poland. Phytopathology 84:201207.

29. Therrien, C. D., Tooley, P. W., Spielman, L. J., Fry, W. E., Ritch, D. L., and Shelly, S. E. 1993. Nuclear DNA content, allozyme phenotypes and metalaxyl sensitivity of Phytophthora infestans from Japan. Mycol. Res. 97:945-950.

30. Tooley, P. W., Fry, W. E., and Villarreal Gon- 
zalez, M. J. 1985. Isozyme characterization of sexual and asexual Phytophthora infestans populations. J. Hered. 76:431-435.

31. Van Tongeren, O. F. R. 1995. Cluster analysis. Pages 174-212 in: Data Analysis in Commu- nity and Landscape Ecology. R. H. G. Jongman, C. J. F. Ter Braak, and O. F. R. Van Tongeren, eds. Cambridge University Press, Cambridge.

32. Zeigler, R. S., Cuoc, L. X., Scott, R. P., Ber- nardo, M. A., Chen, D. H., Valent, B., and Nelson, R. J. 1995. The relationship between lineage and virulence in Pyricularia grisea in the Philippines. Phytopathology 85:443-451. 